\title{
Construction and Value Orientation of City Reading Index System in Digital Reading Era
}

\author{
Zhu Xiaoning, Yang Liwei" \\ Email address: \\ ylwei2010@163.com (Yang Liwei) \\ *Corresponding author
}

School of Political Science and Public Administration, University of Electronic Science and Technology of China, Chengdu, P.R. China

\section{To cite this article:}

Zhu Xiaoning, Yang Liwei. Construction and Value Orientation of City Reading Index System in Digital Reading Era. Social Sciences. Vol. 5, No. 2, 2016, pp. 26-31. doi: 10.11648/j.ss.20160502.14

Received: April 10, 2016; Accepted: May 17, 2016; Published: May 24, 2016

\begin{abstract}
Due to the use of Internet and development of new media, reading demands and reading actions have dramatically changed in Information Age. It is of great importance that how to form a scientific and objective city reading index, which is in accordance with the characteristics of this age. Under this background, many cities in China try to establish their own city reading index system which can effectively promote city reading to systematize, normalize and standardize. This paper is based on the Analytic Hierarchy Process (AHP) method for scientific research, and takes existing index system of city reading for reference while uses the index system of Chengdu for empirical example. By this means, it explains the construction ideas and methods of city reading index systems in digital reading era and comes up with some understandings of value orientation of city reading index systems.
\end{abstract}

Keywords: Digital Reading, Reading Index, Construction System, Value Orientation

\section{Introduction}

Due to the application of Internet and development of new media, reading demands and reading actions have dramatically changed in Information Age. City reading gradually has caught the attention of the government and society. City reading index is a kind of numerical value, which is applied to comprehensively assessing the status and level of city reading development, and it mainly consists of statistical data of reading capital constructions and survey data of citizen reading actions.

Since many cities in China have carried out "Nationwide Reading", reading infrastructure has gradually improved and reading atmosphere has gradually become strong. However, it still lacks of comprehensive systematized index system, which leads to the difficulty of assessing city reading levels objectively. Under this new media age circumstance, index contents, measurement methods and index systems also have to meet this change, so it is urgent to build a city reading index system suiting for the digital reading age. This reading index system can objectively assess the nationwide reading activities, enhance dynamic tracking of reading system construction, strengthen quality supervision of reading activities, and finally promote a flourished development of public culture.

This paper has generalized the evolution of the digital age. Based on AHP method, it has explained the principle and method of the construction of city reading index. Reading index of Shenzhen and Wuhan have been taken into account. As an empirical example, it has constructed the city reading index of Chengdu. Finally, this paper has refined the improvement suggestions for city reading index construction in the digital reading era in order to optimize the existing reading index system and provide some innovative opinions.

\section{Evolution of Digital Reading Era}

With the popularity of digital technology and invention of digital carriers, a new kind of reading mode, i.e. digital reading, has emerged and rapidly popularized. Traditional reading mode is partly replaced and publishing industries such as books, newspapers and magazines face a crisis condition. Meantime, Internet and new media industries have a strong development force. Digital information technology, which is relied on computer, Internet, 
communication, artificial intelligence, multimedia information processing and cloud computing, opens up mankind's cognitive styles, cognitive speed and cognitive span. Gradually, it changes the way of learning, living and thinking. As a result, unprecedented changes have taken place in digital reading era.

\subsection{Evolution of Individual Reading Needs}

In the digital era, computer and Internet technology greatly shock the traditional reading habits and change readers' reading needs. There is more plentiful than ever about reading contexts and more diverse than ever about reading ways. What's more, people's needs for accessing information through reading are unprecedentedly enhanced. Reading motivation is more utilitarian. Reading thinking is more superficial. Reading environment expands to the networking reading environment combined of mobile surroundings and immobile surroundings. At the same time, due to cluster of reading resources and convenience of obtaining ways, reading needs are more individualized. People's needs of reading satisfactions for thoughts, appreciation and excitements have a great increase. As a result, anti-popularization and diversification of reading needs becomes a fashion. Furthermore, with the development of Internet technology, people's needs for entertainment and amusement through reading become much easier, so reading needs tend to be more entertainment-oriented. [1]

\subsection{Evolution of Individual Reading Media}

The rapid development of information technology exerts an influence on the reading carriers and the traditional reading ways are changing in digital reading era. This changes mainly be presented a fact that reading media is changed from paper reading to online reading. Electronic network system has brings about the application and popularity of high technology, then today's reading carriers are not limited paper and various "screens" are becoming new mainstream.

Table 1. National media contact length of 18-70 years old during 2010 to 2014 (Minutes).

\begin{tabular}{lllllll}
\hline Year & Book & News-paper & Journal & Inter-net & Cell phone & E-book reader \\
\hline 2014 & 18.76 & 18.80 & 13.42 & 54.87 & 3.79 & 21.70 \\
2013 & 13.43 & 15.50 & 10.05 & 50.78 & 16.52 \\
2012 & 15.38 & 18.91 & 13.17 & 46.77 & 13.26 \\
2011 & 14.85 & 22.00 & 11.80 & 47.53 & 2.94 \\
2010 & 16.78 & 23.69 & 13.66 & 42.73 & 3.11 \\
\hline
\end{tabular}

From Table 1, it can be concluded that nowadays duration of paper reading is usually low while duration of Internet and phone reading is usually high, and duration of Internet and phone reading is increasing year by year. Compared with traditional paper media, new media has higher contact rate, higher reading duration. The digital reading tendency is obvious. [2]

\subsection{Evolution of Social Reading Environment}

Social reading environments also have an obvious change. Firstly, from the perspective of country, "carrying out nationwide reading activities" has been historically written in the reports of 18th CPC National Congress, and the government work reports also have put forward "advocating nationwide reading". The Party and government both have explicitly point out advocating and launching nationwide reading. Secondly, from the perspective of provinces and cities, Jiangsu, Hunan, Hubei, Shenzhen and some other cities have made some excellent development in the constructions of social reading environments. For example, "Yue Lan Shu" Bookstore for 24 hours in Hangzhou, book bars for 24 hours in Shenzhen, "Midnight Study for 24 hours in Qingdao, Xi'an, Zhengzhou and other 5 cities and so on. These eight districts have reached an agreement on the improvement of social comprehensive reading environments. [3] Thirdly, from the perspective of individuals, because of the rising of "Reading on the Road", attraction of traditional libraries and bookstores as reading places has been a little reduced. At the same time, except reading contents, the influence of comprehensive reading environment has been improved and people's demands for comfortable reading surroundings also further increase. [4]

\section{Principles and Methods of City Reading Index Construction in the Digital Era}

\subsection{Principles of City Reading Index System Construction}

Construction of city reading index should abide by the principle of scientificity. It should be scientific and reasonable in the process: choice of index, design of index weight, data collection, index statistics and so on. As for the selection of measurement index, some factors should be noticed. Firstly, objective index, which has a direct correlation with reading contact points, should be brought into the measurement index. Secondly, core index, which can reflect the actual conditions of city reading and directly impact reading actions, should be brought into index. Moreover, the reading subjects' contents of reading actions also should be brought into index.

Construction of city reading index should abide by the principle of adaptability. On one hand, measurement of city reading index should follow a part of traditional reading index contents and absorb reading index of those advanced districts; on the other hand, measurement of city reading index also need to meet the feature of digital reading era and meet the transformation from traditional reading modes to 
new media reading modes. What's more, during the process of setting measurement index, contents of digital reading, contact rate of new media and measurement of reading duration all should be fully considered. It also needs to fully ensure the objectivity and comprehensiveness of city reading index under background of the digital reading era.

Construction of city reading index should abide by the principle of guidance. In consideration of some negative effects of digital reading, construction of city reading index system should possess some characteristics of guidance. In the process of index selection and weight assignment, the balance between paper reading and digital reading should be noticed. It is necessary to guide a balanced development among various reading media, guarantee quantity and quality of reading, increase reading duration and reasonably guide upgrade of people's cultural qualities. Through construction of the index, the action of reading should be promoted. [5]

\subsection{Methods of City Reading Index System Construction}

In the index system of city reading index measurement, the effects and influences of each index factor are different. In order to more reasonably assess the level of city reading, there is a need to give weights to these index factors according to the different influences of every index factor. This study will take Analystic Hierarchy Process (AHP) to deal with the different index weights and which is more reasonable.

\subsubsection{Establish Hierarchial Structure}

Hierarchial structure is an abstract concept about the structure of a certain target system, and it is built in order to investigate the interrelation between the factors and interaction of functions in the system. Hierarchial structure is a kind of tower-type structure and contains target level, rule level and index level. This kind of structure plays an important for internal analysis in the system of city reading index measurement.

\subsubsection{Establish Judgement Matrix}

After the construction of hierarchial mode, it is clear for the hierarchial construction relationship between up level and down level. However, the importance of the internal factors at the same level is still different, so there is a need to go on the second step: establishing judgement matrix. Judgement matrix aims at making a pairwise comparison of relative importance among the factors at the same level in the hierarchial structure mode.

Table 2. Structural style of judgement matrix.

\begin{tabular}{lllll}
\hline Ak & B1 & B2 & $\ldots \ldots$ & Bn \\
\hline B1 & b11 & b12 & $\ldots \ldots$ & b1n \\
B2 & b21 & b22 & $\ldots \ldots$ & b2n \\
$\ldots \ldots$ & $\ldots \ldots$. & $\ldots \ldots$ & $\ldots \ldots$ & $\ldots \ldots$ \\
Bn & bn1 & bn2 & $\ldots \ldots$ & bnn (bij) \\
\hline
\end{tabular}

If we takes the up level factor $\mathrm{A}$ as the criterion, $\mathrm{A}$ has a domination of its corresponding down factors B1, B2, B3..., $\mathrm{Bn}$. bij signifies that the numerical expression of the relative importance $\mathrm{Bi}$ to $\mathrm{Bj}$ in terms of $\mathrm{Ak}$. Under normal conditions, bij can be given $1,2, \ldots, 9$ and their reciprocal, and the value of bij can be certain through pairwise comparison.

In practical operation, the fill of judgement matrix is to ask the person (usually expert) over and over which element is more important between any two elements and assigns values to the degree of importance according to 1-9. (See Table 3.)

Table 3. Relative importance value table.

\begin{tabular}{ll}
\hline Scale value & Implication \\
\hline 1 & Equal importance \\
3 & Slight importance \\
5 & Obvious importance \\
7 & Strong importance \\
9 & Extreme importance \\
$2,4,6,8$ & Middle-value between two neighbouring judgements above \\
$(1)$ If the comparative judgement between factor $A i$ and factor $\mathrm{Aj}$ is $\mathrm{A}^{\prime} \mathrm{ij}=3$, factor $\mathrm{Ai}$ is slightly more important than factor $\mathrm{Aj}$; \\
$(2)$ If the comparative judgement between factor $\mathrm{Ai}$ and factor $\mathrm{Aj}$ is $\mathrm{A}^{\prime} \mathrm{ij}$, then $\mathrm{A}^{\prime} \mathrm{ji}=1 / \mathrm{A}^{\prime} \mathrm{ij}$.
\end{tabular}

\subsubsection{Make a Hierarchical Ranking}

Hierarchical ranking refers to sequence the value of relative importance of related elements in the same level. Concretely, it is to calculate proper value and eigenvector of a judgement matrix. If we denote maximum eigenvalue of judgement matrix as $\max$, eigenvector corresponding to maximum eigenvalue as $\mathrm{W}, \mathrm{Wi}$, as a component of vector $\mathrm{W}$, should be the Weight Value to sequence corresponding elements and then the formula of $\max$ is:

$$
\lambda \max =\sum_{i=1}^{n} \frac{(A W)_{i}}{n W_{i}}
$$

\subsubsection{Consistency Check}

To make sure the rationality of judgement matrix, a consistency check is needed and the Coincidence Indicator (CI) formula is:

$$
C I=\frac{\lambda \max -n}{n-1}
$$

According to Analytic Hierarchy Process and its concrete operations, based on building index measurement hierarchical chart mentioned above, we can compare first grade indexes in pairs, construct judgement matrices, calculate eigenvector and carry out normalization processing, and through consistency test, get weighting coefficient. Thus 
city reading level can be comprehensively reflected and scientifically and objectively measured.

\section{Construction of City Reading Index System in Digital Reading Era}

Table 4. Comprehensive index of city reading level.

\begin{tabular}{|c|c|c|c|}
\hline Primarily index & Secondly index & Third-grade index & Data sources \\
\hline \multirow{14}{*}{$\begin{array}{l}\text { The comprehensive level of city } \\
\text { reading construction }\end{array}$} & \multirow{5}{*}{ Personal reading behavior } & Comprehensive reading quantity & Questionnaires \\
\hline & & Digital reading rate & Questionnaires \\
\hline & & Reading hour per capita & Questionnaires \\
\hline & & Book-purchasing quantity per capita & Questionnaires \\
\hline & & Reading consumption per capita & Questionnaires \\
\hline & \multirow{5}{*}{ Social reading environment } & Public library quantity & Statistic data \\
\hline & & Book-collections per capita & Statistic data \\
\hline & & Yearly book-collections per million & Statistic data \\
\hline & & Satisfaction rate of library sources & Questionnaires \\
\hline & & Coverage rate of wifi in library & Questionnaires \\
\hline & \multirow{4}{*}{ Overall reading activity } & Reading festivals quantity & Statistic data \\
\hline & & Popularizing rate of reading festivals & Questionnaires \\
\hline & & Participation degree of reading festivals & Questionnaires \\
\hline & & Satisfaction rate of reading festivals & Questionnaires \\
\hline
\end{tabular}

According to the principle of scientificity, adaptability and guidance, based on theoretical support and actual operation, this paper takes Chengdu as an example.

During the process of constructing system of city reading comprehensive index, we should adopt the form of "three index levels, three subsystems". Assessment factors can be divided into three parts: subsystem of reading environment, subsystem of reading activities and subsystem of reading effects. On the basis of this whole framworks, we can form a complete system constructure of city reading index.

Table 5. The balance sheet of comprehensive evaluation index of literary Chengdu construction.

\begin{tabular}{|c|c|c|c|}
\hline Primarily index & Secondly index & Third-grade index & Total weight \\
\hline \multirow{14}{*}{$\begin{array}{l}\text { The comprehensive level of } \\
\text { literary Chengdu construction }\end{array}$} & \multirow{5}{*}{ Personal reading behavior $(0.41)$} & Comprehensive reading quantity $(0.26)$ & 0.1066 \\
\hline & & Digital reading rate $(0.24)$ & 0.0984 \\
\hline & & Reading hour per capita $(0.21)$ & 0.0861 \\
\hline & & Book-purchasing quantity per capita (0.17) & 0.0697 \\
\hline & & Reading consumption per capita $(0.12)$ & 0.0492 \\
\hline & \multirow{5}{*}{$\begin{array}{l}\text { Social reading environment } \\
(0.36)\end{array}$} & Public library quantity $(0.25)$ & 0.0900 \\
\hline & & Book -collections per capita $(0.16)$ & 0.0576 \\
\hline & & Yearly book-collections per million $(0.14)$ & 0.0504 \\
\hline & & Satisfaction rate of library sources $(0.22)$ & 0.0792 \\
\hline & & Coverage rate of wifi in library $(0.23)$ & 0.0828 \\
\hline & \multirow{4}{*}{ Overall reading activity $(0.23)$} & Reading festivals quantity $(0.23)$ & 0.0529 \\
\hline & & Popularizing rate of reading festivals $(0.24)$ & 0.0552 \\
\hline & & Participation degree of reading festivals $(0.28)$ & 0.0644 \\
\hline & & Satisfaction rate of reading festivals $(0.25)$ & 0.0575 \\
\hline
\end{tabular}

Depending on the construction methods of reading index system, city reading index system of Chengdu should set 1 first grade index, then 3 second grade indexes and 14 third grade indexes. Firstly, the importance of every index in each index level has a pairwise comparison. Then, we should select the matrix tables from the experts to give marks. Finally, we can gain the scores of index importance. This study invites the experts of public administration in Chengdu to give marks, then the assessment judgement of individual reading action (A1), social reading environment (A2) and nationwide reading activities (A3), which we have obtained, is $A^{\prime} 13=9 / 5, \quad A^{\prime} 23=8 / 5$, and eventually we gets the corresponding judgement matrix. Through calculating, the weights of individual reading action (A1), social reading environment (A2) and nationwide reading activities (A3) respectively are $0.41,0.36$ and 0.23 . Then we get $\lambda \max$ $=3.002$ throgh calculation, make a consistency check and gain the result, $\mathrm{CI}=0.001$. Through checking the index chart of average random consistency, we can know that when $n=3$, $\mathrm{RI}=0.58$. Therefore, $\mathrm{CR}=\mathrm{CI} / \mathrm{RI}=0.001 / 0.58<0.1$, it can meet the check of consistency. The relative weights of various factors in the subsystems of three index levels are presented in the Table 5 . 
Table 6. Mark sheet of comprehensive reading level of Chengdu.

\begin{tabular}{|c|c|c|c|}
\hline Third-grade index & Actual values (Chengdu) & Standard values (Shenzhen) & Final Score \\
\hline Comprehensive reading quantity & 14.56 & 17.03 & 85.49 \\
\hline Digital reading rate & 60.54 & 61.19 & 98.94 \\
\hline Reading hour per capita & 49.54 & 62.53 & 79.23 \\
\hline Book-purchasing quantity per capita & 20.45 & 27.74 & 73.72 \\
\hline Reading consumption per capita & 417 & 638.02 & 65.36 \\
\hline Public library quantity & 21 & l & 100 \\
\hline Book-collections per capita & 1.35 & 2.83 & 47.7 \\
\hline Yearly book-collections per million & 331.68 & 464.96 & 71.34 \\
\hline Satisfaction rate of library sources & 81.49 & / & 81.49 \\
\hline Coverage rate of wifi in library & 73.21 & 89.79 & 81.53 \\
\hline Reading festivals quantity & 23 & 35 & 65.71 \\
\hline Popularizing rate of reading festivals & 76.45 & / & 76.45 \\
\hline Participation degree of reading festivals & 65.38 & l & 65.38 \\
\hline Satisfaction rate of reading festivals & 69.2 & l & 69.2 \\
\hline
\end{tabular}

According to the index system, questionnaires have been designed and nationwide survey undergone. After that, the data standardization has been applied, while the index is processed by dimensionless method. Furthermore, relative data of Shenzhen municipality is chosen as standard value, and it is required to collect materials and analyze data. This survey gives out 4,500 questionnaires, collect 4,157 valid samples and reach a recovery rate of $92.37 \%$, covering the citizens of main urban areas and districts and counties. After collecting, analyzing statistics, and consulting statistical materials, the survey arrives at the real data of various indexes at third-grade reading indexes in Chengdu, and applies the method of actual value dividing standard value to the result with dimensionless method, and finally reaches the comprehensive score of Chengdu. According to the confirmed index weight and collected statistic, the comprehensive score of city reading index could be got by the formula following:

$$
Q=\sum_{i=1}^{13} W i X i
$$

The comprehensive evaluation score of Chengdu reading construction:

$\mathrm{Q}=(0.1066 * 85.49)+(0.0984 * 98.94)+(0.0861 * 79.23)+(0.0697$

$* 73.72)+(0.0492 * 65.36)+(0.09 * 100)+(0.0576 * 47.7)+(0.0504$

$* 71.34)+(0.0792 * 81.49)+(0.0828 * 81.53)+(0.0529 * 65.71)+(0$ $.0552 * 76.45)+(0.0644 * 65.38)+(0.0575 * 69.2) \approx 78.47$

\section{Value Indicators of the Construction of City Reading Index System}

\subsection{Index-Integrated Digital Reading Project Is the General Development Trend}

The prevalence of digital reading is of multiple adjustable reasons as it is the inevitable product of the intersection of times, technology and cultural development. In digital times, the behavior of digital reading has already been the major contents of digitalized way of surviving for people, so it is important to understand the special significance of digital reading in regard to social and cultural transformation from an evolving and positive perspective. In the city reading indicator system, more indicators should be integrated related to the elements of digital reading, with the proportion and weights of these elements increased gradually so as to guide digital reading better serving the continuation of culture. [6]

\subsection{Index Leads Digital Reading to Enhance City Reading Capability}

\subsubsection{To Optimize Reading Environment by Means of New Media}

It can be gradually tried to include some new media index in city reading index system by introducing public reading platform such as app, e-reading and weixin pushes as evaluation indicators in the future, thus to optimize public reading platforms by new media.

\subsubsection{To Provide Special Services of Digital Reading}

Step by step, try to include data mining, data analysis and other elements within city reading index system to lead personal reading services based on data analysis.

\subsubsection{To Expand Digital Reading Resources Through Digital Reading}

Progressively add the paperless reading, library search optimization and other elements to the index system, fully survey the situation of digital resources in order to guide the public platform for the integration of digital information resources for the construction of digital information resources platform of public reading. [7]

\subsection{Index Leads to Balance the Development of Digital Reading and Traditional Reading}

Digital reading, in certain degree, is inclined to bringing people sallow reading, recreation and over-consumption. It cannot fully substitute the traditional reading no matter it's in the current stage or in the future. Therefore, in the construction of city reading index system, the elements of digital reading index cannot be added blindly. [8] The traditional reading hardware, paper reading amount and paper reading 
consumption shall still be the key factors for evaluation so as to maintain the weights of traditional reading projects. It is our goal to lead proactively the development of deep reading and knowledgeable reading and to promote the adjustability of reading consumption so as to enrich people's mental world and cultural life, build good city cultural atmosphere and promote the prosperity and development of city culture. [9]

\section{Conclusions}

In conclusion, the digital media influence on society culture development is gradually growing in the period of society transformation. Built on the basis of print media, traditional culture, politics and economy is gradually coming apart. In this new reading era, although the boundaries among learning, relaxation and entertainment are become fuzzy, the dividing lines of culture growth, culture consumption and culture economy are disappearing, the shaping force of reading is the same and it deeply affects our lives. That's why from the perspective of city reading construction, it needs to meet the change of times and try to reach the balanced development of all kinds media. However, how to quantify the balance point is the difficulty in future research.

\section{Acknowledgements}

This work is supported by the Complex Liberal Arts Laboratory of SPSPA and the Research project of Chengdu Nationwide Reading Promotion and construction (Grant No.2015000424).

\section{References}

[1] Yang Min. The Change of People's Reading Demands in Digital Age and the Countermeasures [J]. Library and Information Forum, 2012(5), pp 49-53(in Chinese).

[2] Nie Zhenning. The National Reading Situation and
Significance of Nationwide Reading Movement [J]. Modern Publishing, 2015(1), pp5-10 (in Chinese).

[3] Zhang Han, Wang Xiaohua. City Reading Index: Concept, Method and Measure [J]. Research on Publishing, 2016 (2), 82-85 (in Chinese).

[4] Li Xinxiang. Research on the Evolution of National Reading Behavior and Its Countermeasures [D]. Wuhan University. 2013 (in Chinese).

[5] Xia Lixin, Li Chenglong, Sun Jingqiong. An Exploratory Study on the Construction of Standards and Assessment of National Reading on Multi-dimensional Integration [J]. Journal of Library Science in China, 2015(11), pp 13-28 (in Chinese).

[6] Fan Xuemei. Research on the Promotion of Reading by Public Library in Developed Areas [J]. Library Forum, 2007(2) (in Chinese).

[7] Shen Wei. Digital Reading: from Cultural Consumption to Meaning Production [D]. Wuhan University, 2013 (in Chinese)

[8] Liao Xian, Zhu Xinhua. A discussion about the reading assessment strategy based on the recent development of International Reading Assessment Project [J]. Global Education, 2010(12), PP53-59 (in Chinese).

[9] Wang Shiwei. Study of the international metropolitan library evaluation index system [M]. Shanghai: Shanghai Scientific and Technological Literature Press, 2009. (in Chinese)

[10] Xia Lixin, Li Chenglong, Sun Jingqiong. An exploratory study on the Construction of Comprehensive Evaluation Index System of National Reading. Take Example of the National Reading Comprehensive Evaluation Index System of Wuhan City [J]. Documentation, Information and Knowledge, 2015(4): 106-112 (in Chinese).

[11] He Mingsheng, Bai Shuying. Network Interactivity: from Technical Environment to Living World [M]. Beijing: China Social Sciences Press, 2008. (in Chinese).

[12] American Library Association. Public library service: a guide to evaluation, with minimum standards [EB /OL]. [2015-06-01]. http://babel.hathitrust.org/cgi/pt?id=uc1.b3926658;view=1up;se $\mathrm{q}=46$. 